\title{
Tourism Boom by Islamic Art Spiritual Attractions in Iran Perspective Elements
}

\author{
Susan Khataei \\ Assistant Professor, Department of Graphic Design, Faculty of Architecture and Urban Design, \\ Shahid Rajaee Teacher Training University, Tehran, Iran
}

\section{Doi:10.5901/mjss.2016.v7n4s1p40}

\begin{abstract}
Iran is one of the ten first countries in the world on the subject of tourism attractions. Iran, the land of four seasons simultaneously, and historical and scientific - cultural buildings is of interest for many tourists. Various works of Islamic art in the perspective of Iran that have been arisen in different periods and regions all have the same message and truth and have a sign of coordination and the greatness of Islamic civilization and culture. The artistic unity that stems from ideological unity, is able to attract many audience and can transcends the boundaries of time and place and communicate spiritually with all its contacts and believers. Islamic art and architecture is derived from religious sources and has an appearance (form) and the inside. Forms are created to give meaning and generally in Islamic art, nothing is void of the "meaning". General feeling of foreign tourists by observing Islamic-Iranian monuments is along with surprise, admiration and a sense of spirituality. In this study, the role of decorations in mosques and shrines in Iranian - Islamic architecture to establish spiritual relationship with the audience is emphasized. This is an applied research with analytical descriptive method which have been done based on observation and documentary studies. The results suggest the importance of spiritual relationship of audience with the works that is effective in tourism attraction.
\end{abstract}

Keywords: spiritual art, tourism, Islamic-Iranian architecture, mosques and shrines (Boqe).

\section{Introduction}

Quran has invited people to tourism and traveling in the world many times; because man in tourism observe the works of ancients and signs of the power of God on earth.

Wikipedia says: World Tourism Organization in 1995 issued a final definition: A set of activities of the person or persons who travel to a location other than their normal place of residence and reside there at least one night and their purpose of travel is to spend leisure time. Of course, objectives such as employment and income are not included. Accordingly, those who are included in this definition are called tourists. Tourism has various aspects, spirituality is the most important one. So, this should be a priority for officials in the destination city to act effectively as a host in establishing an optimal relationship and creating a good memory.

"What we have in our country as a tourist attraction, especially scientific, cultural and historical buildings, are an expression of our culture and representing something that has remained for us since long past and the symbols now can be used to develop tourism industry" (Karroubi, 21: 2003).

In research background according to findings of Imani Khoshkhou et al., "Iranian - Islamic architecture has a prominent role in the perception of European tourists from Iran. General feeling of tourists to Iranian - Islamic buildings which have been visited is a feeling full of amazement, admiration and a sense of spirituality (Imani Khoshkhou, 78: 2006).

This research examines the methods of providing meaning in Islamic architecture as a symbolic element with ornaments and embellishments. These elements in inscriptions and motifs of tiling of mosques and tombs are visible and play an important role in attracting tourists spiritually.

\section{The Importance of Tourism}

- Revenue: When tourists entre a country, they necessarily have to pay some costs in that country. These costs, through the exchange currency they enter the host country, cause the economic boom of the host country. On the other hand, they also brought memories and meanings received from the observed works and samples with them. That's why the tourists are called invisible exports.

- Employment: With the development of tourism, the context is provided for job creation and this is very useful 
for countries which are facing with young job seekers. For every ten tourists coming into the host country, a job opportunity is provided in the country.

\section{Tourism Features in Iran}

A. Land of four seasons: Because of its size and geographical spread in the map of earth, Iran is called the four seasons' country. So that when the heights in the north Iran is snowy winter, the south of Iran enjoy a spring nice temperature and bright sunshine on the Persian Gulf. Natural attractions and beautiful scenery of four simultaneous seasons is one of the reasons for tourist attraction, but more importantly is visiting the monuments and historical and artistic centers of Iran.

B. Iranian - Islamic architecture: While it has a wide diversity, has a major role in formation of European tourists' idea from Iran. One of the most notable of them is Naqsh Jahan square and Sheikh Lotfollah Mosque in Isfahan that are visited by tourists.

"In tourism industry, the destination message from the tourist view and his emotions about the experience of destination from the perspective of tourist and the his emotions about the experience of destination and in general terms, his perception to the destination which is called "tourism destination image" has a very broad concept with a rich literature and its results are directly used by the experts in this area. The concept in the whole process of tourism, from the decision to reminisce, affect the consumer behavior." (Jenkins, 1999)

The glory of Iranian architecture is a manifestation of the historic, artistic, religious greatness and civilization of Iran. Iranian with their belief in religious teachings, have left magnificent works in the architecture of mosques and tombs during the Islamic period with the efforts of craftsmen, architects, artists, donors, kings and rulers who seek spirituality and godliness.

\section{Decoration and Spirituality in Mosques and Shrines}

Arabic word "Zinat" is used in Qoran frequently, "in forty-two verses of the Quran, the word "Zinat" and its derivatives are given in Quran forty-six times" (Ansari, 63: 2002).

In wisdom and teachings of the Quran, in addition to a positive sense, in some cases it had negative meaning and it was also called as the tools of Satan. So decoration only in its real place, refers to the divine tradition. While, decoration expresses the real world is not a true expression of the real decoration and so will be unsteady.

"Words decorations and decorations in combination with the architecture in the Islamic-Iranian culture, in addition to the physical aspects which is very versatile, can reefer to the esoteric and spiritual aspects of architecture" (Alavi Nrjad et al., 4: 2011). This section contains 6 parts that are trying to express the role of decoration in the service of Iran architecture and thus promotion of spirituality in Islamic monuments such as mosques and shrines.

- The most important part of every city is its temple.

"Among the organs within each town and village, houses of worship always had and have a special place, and are more visible and dramatic than the other buildings. That is why it has a place everywhere in the village (Pirnia, 37: 2007). The importance of this part accelerates and strengthens the process of art development in the service of meaning and thus spiritual art in mosques and shrines of Iran.

- Decorative elements along with spirituality, in the great mosques with wide spaces offer a magnificent and materialistic paradise for worship.

"Art can ravish the audience about the glory deeper than what is offered by the work. Basically, theology and art relate to each other. Experts need theology so the art facilitates the expression of inexpressible matters for them and art need theology professionals to clearly express the divine affairs" (Lodetbar, 58: 2004).

- Ornaments and embellishments are used as symbolic elements.

In the mosques, the use of ornaments and embellishments as symbolic elements for spiritual communication with God was common since the first historical examples and was gradually expanded. Of course, there are two broad views on decoration: one is based on the external (physical) performance and the other based on the meaning and content. "Those who have a formative look to decorations believe that decorations are mere a superficial coverage and lack any religious and cultural meaning and concept which is used to cover the underside rough surfaces. In contrast to this view, people like Burckhardt believe that this designs have a mystical and contemplative ahistorical (timeless) nature. From this perspective, decorations are not only appearance but also have various levels with symbolic and transcendent meanings. In the meantime, Oleg Grabar has a different opinion. In his view, decoration is composed of some mediations among objects and on 
the other hand the observers. Arrays are filters that transfer messages and symbols and even consciously or unconsciously pleasures to communicate with the audience best" (khansari and Naghizadeh, 4: 2013).

- One of the most important and most direct parts in transferring meaning to the audience are inscriptions. In inscriptions of mosques and shrines, the spirituality lying in (the verses and hadiths) are directly expressed besides the beauty of the calligraphy. The most obvious art is calligraphy in mosque architecture that reflects the writing of divine words in a small paradise called mosque. "Letters in the inscriptions contain symbols and symbolic concepts" (Khosrowjerdi, Mahmoud, 12: 2014).

"Calligraphy essentially consists of meaning, advising, respected and sacred meaning. Calligraphy in space is not applied in a way that must be read, it seems that designer feel that the presence of script in the space is more important and more effective for audience than reading it and accessing its implications. Inscriptions are only visual elements that directly carries meaning and from the perspective of the image (appearance) and the content and context, are of great importance in the Islamic period buildings. Inscriptions are also important and interesting even in the eyes of non-Muslims. Professor Pop, a famous Iran scholar, says inscriptions which create lots of excitement in complexity of 4 lines, should really be examined. In place of the pure design, they are worthy of the highest praise, but yet Muslims know that they have inner properties. "(Maki Nejad, 30: 2009).

- Tiling was a proper coverage and canvas to present arabesques and Khatai designs in Islamic architecture, which was formed based on religious beliefs. Tiles, for two main objectives - one is the strength and the other decorations - has reached the highest level of growth and excellence in Islamic art. "After the advent of Islam, and in the third century AD in the city of Samarra, the Abbasid capital, tiling was common. Iranians before the introduction of tiling, used painting and color in the decoration of buildings and ways of painting under the glaze was common in pottery centers in the north and northeastern Iran. During Safavids, also notable developments has happened in this area and all types of mosaic tiling, seven colors and clay tile were used in buildings "(Talebpour, 3: 2008). The art was boosted during the reign of the patriarch, Timurid and Safavid. "Mosaic tile is formed from cut out pieces of tiles which was collected from different designs and colors and form a larger piece together. Seven colors tile which is very popular is originated from clay tiles and paint the desired design on it". (Shayestehfar, 31: 2010) "Decorative tiling of Islamic era buildings are treasures that display the religious beliefs and aspects of culture and art in this era". (Kayani, Fateme, p. 118)

- Decorative and plant abstract motifs have been used in tiling of mosques and shrines and by creating an imagination of divine gardens on earth, are effective in creating a spiritual sense for tourists. Perhaps the reason for the use of Khatai and arabesques motifs, which are a kind of abstract plant designs and are inspired by the pattern or fact of plants were to induce a sense of freshness and vitality in the space of mosques. Arabesque motifs are repeated circular, often symmetrical and asymmetrical mazes and circulations, they can be reminiscent of the twisting stems of plants. Figure 1 and 2

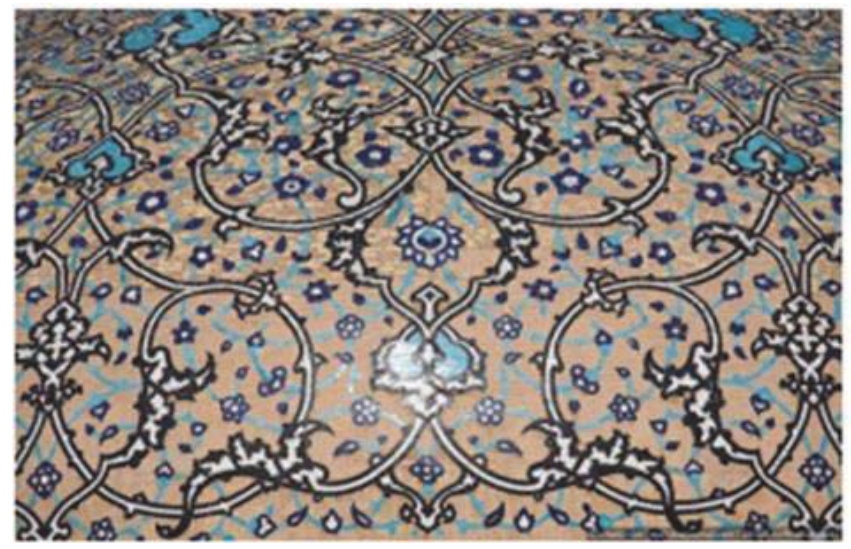

Figure 1: Arabesque patterns of the dome of Sheikh Lotfollah mosque with dark border which has delicate Khatai patterns inside it. www.google.com 


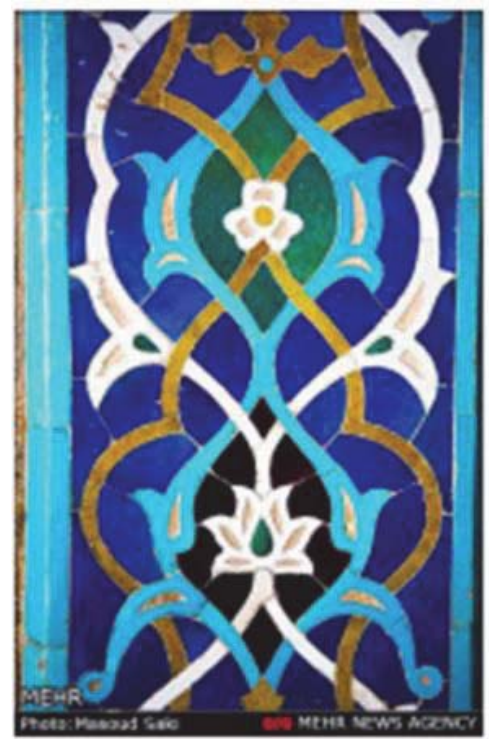

Figure 2: Arabesque motifs of grand mosque in Yazd. persian-star.org

"Khatai designs compared to Arabesques have less abstraction. Khatai designs which have love-like stems, include various leaves, buds, pots and flowers. The Khatai designs are the plants and flowers and shrub like motifs that are moving with elegance and fine among the Arabesque designs. Shah Abbasi flowers or trumpet vine, and other delicate fine flowers that are found in nature, but somehow the artist pen has created changes to the original form" (Asna-Ashari, Shayestehfar, 11: 2011). Figure 3 and 4

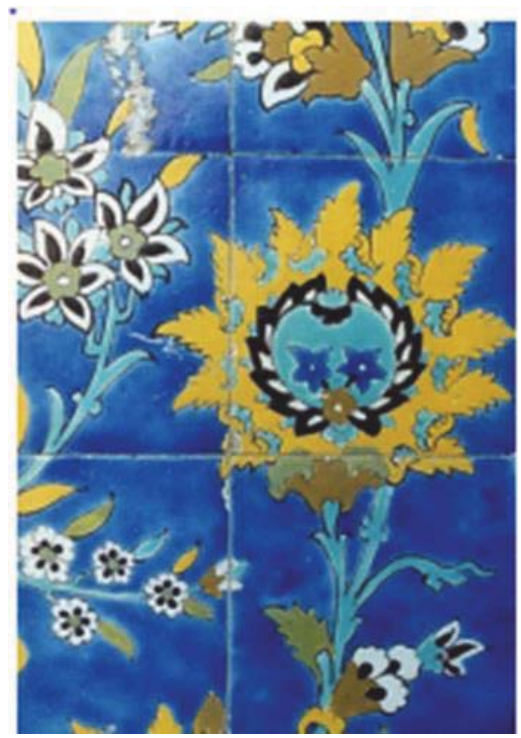

Figure 3: Khatai motifs on the walls of Sheikh Lotfollah mosque. www.google.com 


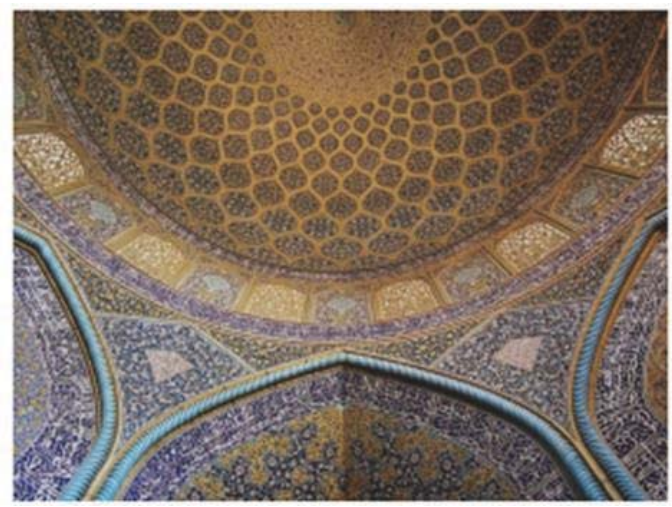

Figure 4: Tiling on walls of Sheikh Lotfollah mosque. fa.wikipedia.org

7-4- Graves and the shrines: After the shrine of Imam Reza in Mashhad, the most prestigious and the most important Iran's historical - religious shrine, there are places in most towns and villages where have a special reputation in comparison to other Islamic buildings (except mosques).

"Holy places and religious shrines, especially the tomb of antecedents of Imams and Shiite great people are called shrine (Boqe) ... although from the perspective of the common people of the village all the shrines are the tomb of antecedents of Imams, but by reference to history, we find that many of them were local princes, good people of the villages, killed in rural and local conflicts and peasant uprising martyrs" (Khakban, P. 96, 2002).

"Boqe is where popular culture flows through it and is a proper ground for keeping alive the popular beliefs and ideas of simple and innocent people" (ibid., P. 97). Usually people are responsible for maintaining the monuments.

In some towns and villages, the Bekaa are in adjacent of natural landscapes. For example, in Guilan province, Lahijan city besides the abundant natural attractions (green nature), the decoration and architecture of historical-religious monument "Sheikh Zahed Guilani", particularly its special graffiti attract the attentions." Graffiti art is directly related to architecture decoration and is not in contrast with it, because one of the main aspects of graffiti is decoration and beauty of environment and architecture" (Alavi Nejad et al., 8: 2011). Of course, this topic requires further research.

Shrines like the mosques are the elements of decorating building to make a sense of spirituality in the audience. Tourists besides understanding the spiritual atmosphere of such places, get familiar with religious culture and indigenous and traditional values in these areas. Exploring and scientific knowledge of different cultures by some tourists paves the way for presence of university research tourists.

\section{Islamic Art}

Islamic art has a huge trove of deep spiritual meaning and wisdom, because this art is rooted in deep divine and spiritual thinking foundations. This art, sometimes by creating new forms and sometimes by utilizing images and art forms of past such as ancient Iran and pre-Islamic Iran and with giving new attitude and meaning to them, establishes a very rich culture in Islamic civilization. (Shahbazi et al., 224: 2012).

Art is an important element of Islamic culture. The main features of Islamic art are:

1. Creating a sacred space with an emphasis on spirituality of place;

2. Displaying the intrinsic values of matter and giving perfection to it;

3. Strengthening the relationship between man and the supernatural;

4. Expressing spiritual qualities and their preference to beauty (showing originality and truth);

5. Epistemology and paying attention to meanings and interpretations of the basic concepts;

6. Reliance on wisdom;

7. Physical and intuitive expression of artist perception;

8. Allegory, symbolism and encoding (Naghizadeh, 69: 2005).

"Islamic art creates a vacuum and eliminates all depressions and lustful desires of the world and replace a system which shows balance, serenity and peace. This can refer to central importance of architecture in Islamic art" (Burckhardt, 50: 1997). 


\section{Conclusion}

Humanist nature of man and his inner desire to climb a lofty place, shapes the built environment of his life and as a medium, conveys meaning and guides subsequent generations accordingly. (Pakzad, 4: 2013)

"The purpose of Islamic architecture in general is to create an environment that help people in the process of recognition of his immortality and his evolution towards absolute truth and guides him from the darkness of understanding to eternal light" (Zolfagharzadeh, 40, 2014).

"Art, in its most general definition in the Islamic vision, is a way to honor the material spiritually and decoration is the only way to get material rid of the world" (Enayat, 34: 2008).

In general, Islamic art just keeps things that are important for all times. The reason for amazing development of geometry in Islamic art is this issue. Repeating inscriptions from the Koran on the walls of mosques and monuments recall the fact that Islamic art is founded on spirituality.

Life and timelessness and immortality of art elements and architecture of Iran historical monuments are of interest to tourists. There are alive patterns in these works which has saved them from forgetting in the time. They have a pure essence in material beauty which close the spiritual and non-materialistic meanings to the mind of tourists. "Timeless and placeless" buildings belong to all ages and the world and also are of interest to tourists. In making them, the perfect models are derived from a more pure truth and are in unity with the other components of the built environment. Decorative elements derived from such pure models can express themselves and invite the audience to them. Patterns are derived from sharing religious beliefs, thoughts and hearts of artists and their contemporary culture and have created unparalleled power in Iran art and architecture.

\section{References}

Imani Khoshkhou, Mohammad Hossein et al., "The impact of Iranian - Islamic architecture on conceptual image of European tourists from Iran". No. 11 and 12, Spring 2006, pp. 57 - 80.

Pakzad, Ahmad. "An Introduction to the role of murals in humanist urban identity". Journal of Art study. No. 1, 2013

Karroubi, Mehdi. "Culture of tourism". Tourism Management Studies, second edition, 2003: pp. 21 -48.

Kiani, Fateme. An introduction to the art of tiling in Iran. Moon of art book, No. 153. June 2011. pp. $118-125$.

Ansari, Mojtaba. "Decoration in architecture and art of Iran, the Islamic period with an emphasis on mosques". Art teacher magazine, Vol. 1, No. 1, autumn 2002.

Pir Nia, Karim. Iran Islamic architecture. Tehran, University of Science and Technology, 1993.

Lodatber, Shannon. Religion and Art. Translation: Najarian, Afsane. Tehran, Omran Printing, 2004.

Khansari Sheida, Dr. Naghizadeh Mohammad. "Comparative study of arrays in mosques in Varamin and Nain". Journal of Negareh, No. 29, 2013.

Khosrowjerdi, Narjes, Mahmoudi, Masoud. "Mosque and regeneration of Iranian-Islamic meanings, concepts and symbols" Ninth symposium on development of science and technology, first commission: National conference on architecture, urbanism and sustainable development with a focus on reading Islamic-Iranian identity in Architecture and Urban Planning, Azad University of Mashhad, Khorasan Razavi, 2014.

Maki Nejad, Mahdi. "The evolution of third inscriptions in Iran architecture (from the Safavid to Qajar)", Journal of Negareh, No. 13, 2009.

Talebpour, Faride. "Review of motifs of Abaqakhan palace tiling in Takht-e-Soleiman", Negareh, No. 8-9, 2008.

Shayestehfar, Mahnaz. The importance of tiling in religious buildings of Iran. Moon of Art Book, No. 144, 2010, pp. 35 - 28.

Asna-Ashari, Nafiseh. Shayestehfar, Mahnaz "Decorative motifs of Timor Qurans and Tiling in Gohar Shad Grand Mosque", Journal of Islamic art studies, 2011, №. 15.

Khakban, Mojgan. "Graffiti's of Imamzadeh and Bekaa of Lahijan region". Moon of Art Book, (45), 2002, pp. 45 and 46 - 96 to 101.

Alavi Nejad, Seyed Mohsen. Nadalian, Ahmad. Kafshchiyan Moghaddam, Asqar. Shirazi, Ali Asqar. "Comparative study of application of two architecture and mural decorations terms in Islamic Art (1)", Negareh, Issue 15, 2011.

Shahbazi, Majid. Mirzaee, Qasem. Mohammadi Kia, Mohammad. "The role of the natural elements and symbolism in Islamic mysticism and art", Journal of Islamic mysticism, Volume 8, №. 32. Summer 2012: pp. 223-242.

Naghizadeh, Mohammed. Foundations of religious art in Islamic culture. Vol. 1, Ed. 1, Tehran, Islamic Culture Publications Office, 2005.

Burckhardt, Titus, "Eternal values of Islamic Art", in: Proceedings of the immortality of art, collectors: Avini, Seyed Mohammad, translator Nasr, Seyed Hossein, Tehran, Barg, 1997.

Enayat Tofiq, "elements of Iranian identity and culture in the works of Islamic art," Art Month book, Sept. 2008.

Zolfagharzadeh., H., "An Analysis of Attitudes towards Islamic Architecture", Journal of Islamic architecture, $1^{\text {st }}$ year - No. 3, 2014

Jenkins, O. H (1999), Understanding and measuring tourist destination images, Journal of Tourism Research, 1, 1-15. 